\title{
Perceived Epistemic Authority (Source Credibility) of a TV Interviewer Moderates the Media Bias Effect Caused by His Nonverbal Behavior
}

\author{
Refael Tikochinski $^{1}$ D Elisha Babad ${ }^{1}$
}

Accepted: 30 December 2021 / Published online: 28 January 2022

(c) The Author(s), under exclusive licence to Springer Science+Business Media, LLC, part of Springer Nature 2022

\begin{abstract}
The Media Bias Effect (MBE) represents the biasing influence of the nonverbal behavior of a TV interviewer on viewers' impressions of the interviewee. In the MBE experiment, participants view a 4-min made-up political interview in which they are exposed only to the nonverbal behavior of the actors. The interviewer is friendly toward the politician in one experimental condition and hostile in the other. The interviewee was a confederate filmed in the same studio, and his clips are identical in the two conditions. This experiment was used successfully in a series of studies in several countries (Babad and Peer in J Nonverbal Behav 34(1):57-78, 2010. https://doi.org/10.1007/s10919-009-0078-x) and was administered in the present research. The present investigation focused on the interviewer's source credibility and its persuasive influence. The viewers filled out questionnaires about their impressions of both the interviewer and the interviewee. A component of "interviewer's authority" was derived in PCA, with substantial variance in viewers' impressions of the interviewer. In our design, we preferred the conception of Epistemic Authority (Kruglanski et al. in Adv Exp Soc Psychol 37:345-392, 2005)—based on viewers' subjective perceptions for deriving authority status - to the conventional design of source credibility studies, where dimensions of authority are pre-determined as independent variables. The results demonstrated that viewers who perceived the interviewer as an effective leader demonstrated a clear MBE and were susceptible to his influencing bias, but no bias effect was found for viewers who did not perceive the interviewer as an effective leader. Thus, Epistemic Authority (source credibility) moderated the Media Bias Effect.
\end{abstract}

Keywords Media-bias $\cdot$ Epistemic-authority $\cdot$ Nonverbal behavior $\cdot$ Source credibility

Refael Tikochinski

refael.tikochinski@mail.huji.ac.il

1 Seymour Fox School of Education, The Hebrew University of Jerusalem, Mount Scopus, Jerusalem, Israel 


\section{Introduction}

This research extends a series of experimental studies on the Media Bias Effect (MBE, Babad \& Peer, 2010; Babad, 2005) in the context of a political TV interview. The MBE experiment (used in all studies in the series, including the present investigation) examines the influence of the nonverbal behavior of a TV interviewer on viewers' evaluations of the interviewed politician. In the experiment, viewers watch one of two versions of a 4-min political interview conducted by an unknown TV interviewer with an unknown politician, both speaking a foreign, incomprehensible language (Hebrew; Israeli participants view the video channel only to prevent verbal comprehension). Viewers subsequently rate their impressions and evaluations of the interviewee. The experimental manipulation consists of the interviewer's friendliness, with him being friendly toward the interviewee in one condition and hostile to him in the other. All of the interviewer's clips were taken from two previously broadcasted, extremely important interviews in a National Election campaign in Israel. In the experiment, a confederate serves as the identical interviewee in both conditions, with the friendly (in one condition) and hostile original interviewer clips (in the other condition) characterizing the interviewer's behavior.

In the series of studies, the MBE experiment was replicated in several countries (Babad, 1999, 2005; Babad et al., 2012a, 2012b), was validated and meta-analyzed (Babad \& Peer, 2010), and was found to be consistently effective in creating a measurable media bias effect caused exclusively by the interviewer's nonverbal behavior. The ecological validity of the experiment stems from the fact that the interviewer was a leading TV broadcaster, and the particular interviews from which the clips were taken have been considered as the top political interviews ever conducted in Israel. Therefore, this experiment serves as an excellent platform for investigating the relations between nonverbal media bias and a variety of social psychological constructs and phenomena.

The present study was first intended to replicate the MBE experiment in the 2020s-a period of changing public atmosphere and reduced trust in media equity. Beyond the necessary replication of the experiment, the main goal was to investigate an aspect that has not been examined thus far, namely viewers' perceptions and judgments of the interviewer (beyond the dependent variables of their judgments of the interviewee) in order to explore the potential moderating effect of the interviewer's source credibility and epistemic authority in influencing viewers' impressions of the interviewee.

\section{Nonverbal Behavior in Political Broadcasting}

Concerns about the role of nonverbal behavior and nonverbal communication in the public media have been expressed over the last decades in a steady stream of publications of various forms. Television broadcasting involves powerful video and audio aspects over and beyond the verbal content, and these are most often carefully staged and enacted in attempts to persuade the viewers in particular directions. People generally accept that commercial advertisements are intentionally biased and deviate from being objective and truthful. But it had been consensually held in the past in Western culture that public broadcasting (in news reporting, documentation, and political interviews) should be unbiased and abide by rules of objectivity, even-handedness, and fairness to all. The Kennedy-Nixon televised 1960 debates probably represent the most notable historical landmark. Those 
debates created awareness that the candidates' own nonverbal behavior could be influential on viewers.

Israel held strict explicit norms about the required fairness and objectivity in the public media. The Israeli National Broadcasting Authority published in 1995 "The Nakdi Document" (Rogel \& Shejter, 1995), which detailed guidelines and legally-binding regulations for objectivity in public broadcasting. The guide explicitly prohibited broadcasters from expressing their personal views and warned them against trying in any way to influence viewers in line with their personal political bent. In democratic countries, various authors, public figures, and civic organizations raised havoc in criticizing biased political broadcasting in the public media (e.g., Elliott 1986).

Over the years, the media discourse has become blunt, more aggressive, and less cautious, with almost no pretense of maintaining old ethical norms. Today, even published (presumably objective) election polls are mistrusted (Cohn, 2020; Price \& Stroud, 2005; Sheffield, 2018). Concerns about the biasing influence of nonverbal behavior and nonverbal communication are certainly part of the larger problem of media fairness and objectivity (see Dumitrescu's, 2016 article on nonverbal communication in politics and Boxwell's, 2018 paper on measuring nonverbal media bias, 'slanted images').

Two distinct varieties of nonverbal media research were salient over the years: One concentrated on nonverbal behavior of individual figures, investigating appearance, facial expressions, and specific gestures of presidents, politicians, anchor TV personalities, and other figures, focusing on individual nonverbal behavior. The other variety focused on dyadic nonverbal communication in TV interviews and televised debates, searching for potential media bias.

In the first group, early studies on presidential elections in the 1980s evoked much interest. Friedman et al. (1980a, 1980b) and Mullen et al. (1986) examined the facial expressions of the leading networks' anchorpersons when they uttered the names of presidential candidates. They reported clear (yet subtle) systematic differences indicative of the anchorpersons' preferences. In these and in numerous later studies in the same vein, researchers suggested that those expressions were latent attempts of hidden persuasion. More recent studies analyzed the appearance and nonverbal behavior of presidential candidates (Banning \& Coleman, 2009; Peng, 2018) and of other politicians in real-life and laboratory situations (Haumer \& Donsbach, 2009; Kilgo et al., 2018). Olivola and Todorov (2010) reported that facial appearance-based trait inferences following rapid exposure can predict electoral success.

The second variety of research involves nonverbal aspects in interpersonal communication during political debates and TV interviews. Grebelsky-Lichtman developed the concept of Nonverbal Communicative Structure (NCS) to characterize politicians' personal styles, integrating verbal and nonverbal aspects and examining patterns of discrepancy and non-discrepancy between them. She applied this model to analyze political debates (Grebelsky-Lichtman, 2016) and televised political interviews (Grebelsky-Lichtman, 2010), and even to analyze the nonverbal behavior of selected male and female heads of state during the COVID-19 crisis (Grebelsky-Lichtman \& Katz, 2020). Similarly, Kinoshita (2020) investigated the integration of verbal and nonverbal behaviors in political interviews in Japan. Additional relevant sources include an analysis of gestures in political interviews (Trotta \& Tonelli, 2021) and Schroder's (2016) extensive analysis of presidential debates.

Babad (1999) investigated the nonverbal behavior of seven TV interviewers to discover whether they treated politicians from opposing camps (and other interviewees) in a differential or an equitable manner. He reported systematic patterns of differential, inequitable nonverbal behavior of all interviewers toward their different interviewees. 
One interviewer conducted two lengthy parallel interviews (90 min. each) with the two candidates for prime minister in an upcoming national election. These interviews were considered by the press as the most important political interviews ever broadcasted in Israel. Despite claiming to follow the dictums of the Nakdi Document (Rogel \& Shejter, 1995) this interviewer supported one of the politicians and was friendly towards him, whereas he disliked the other candidate and was hostile towards him. Judgments of the mixed 143 clips of the interviewer's behavior in the two interviews by 109 non-Hebrew-speaking American judges demonstrated the interviewer's nonverbal bias with an extremely high effect magnitude $(d=2.60 ;$ eta $=0.78)$. This interviewer was later chosen by Babad (2005) for the MBE experiment, with friendly and hostile clips selected from his two broadcasts.

\section{The MBE Experiment: Rationale, Design, and Results}

Claims or complaints about bias are often over-stated. Many advocates find it sufficient to claim that a sender's message has been biased and bent in an overt or a covert attempt to influence receivers. But the complete framework of a bias phenomenon should also include detectable consequences in actually influencing the receivers. Otherwise, although the sender's behavior might have demonstrated bias, the receivers have not necessarily been "biasedx". In the words of the common saying, "the proof of the pudding is in the eating!" The MBE experiment (Babad, 2005) was designed to demonstrate the causal influence of the interviewer's nonverbal behavior on viewers' perceptions and judgments of the interviewee in a controlled lab experiment.

Causal influence of this type is hard to prove. Mullen et al. (1986) provided a causal explanation of the effect of anchorman biased facial expressions when they uttered the names of presidential candidates on viewers' voting behavior, but their evidence was far from convincing. It is very difficult to prove causality in a field study, and the experimental method enables researchers to strictly control various sources of noise variance and to focus exclusively on the relevant variables. This was the rationale for designing the MBE experiment (Babad, 2005).

Groups of viewers watch a made-up 4-min video of a political interview, but they are exposed only to the nonverbal behavior of the interviewer (and of the interviewee) under different conditions (friendly interviewer versus hostile interviewer). They are then asked to rate and evaluate the interviewee on a scale of social attributes and characteristics. And because the nonverbal behavior of the interviewee in the film is identical in the friendly and hostile interviewer conditions, any differences between the two experimental groups in viewers' judgments of the interviewee would necessarily be causal outcomes of the interviewer's differential nonverbal behavior.

In all administrations of our experiment, all viewers could not comprehend the verbal content of the exchanges. Viewers outside of Israel were exposed to the full Video + Audio material but could not comprehend the Hebrew speech, whereas Israeli viewers were exposed to video only without audio, to prevent verbal comprehension (Babad \& Peer, 2010, demonstrated that almost identical bias findings were found for Israeli and nonIsraeli samples).

In the series of studies (Babad, 2005; Babad \& Peer, 2010; Babad et al., 2012a, 2012b) the MBE experiment was replicated, validated, and meta-analyzed in four countries. The various results demonstrated that: The framing of the interviewee as a professor versus a politician in one study did not affect the MBE, but framing the interviewee as "one of us" versus "one of them" in political affiliation strongly influenced the ratings of the 
interviewee; changing one isolated frame of the interviewee in the film from a stern, serious speaker to a beaming person (when talking about his granddaughters) reversed the bias effect; multiple biases can emerge from viewing the interview (media bias effect and a halo effect); and the MBE can be debiased to a large extent by a cognitive intervention (instruction to be objective) and by a high school course in media literacy.

To summarize, the MBE experiment is a solid, reliable, valid, and easy-to-use experimental instrument for producing and measuring nonverbal media bias, and it can be used for investigating various basic and applied questions about cognitive and social phenomena and their associations with nonverbal media bias. The present study was designed to replicate the experiment again in the 2020s, and to examine an important social psychological phenomenon that has not been investigated yet in this series of studies, namely source credibility (or Epistemic Authority) of the interviewer.

\section{Source Credibility, Epistemic Authority, and the Media Bias Effect}

Source credibility is a critical conceptual link in the path of the persuasion process. It consists of the communicator's characteristics that implicitly influence acceptance of persuasive messages. In the case of the MBE experiment, for the interviewer's nonverbal behavior to influence viewers' impressions of the interviewee, they must accept the interviewer as a credible source. Otherwise, their ratings of the interviewee would not differ between the friendly and hostile interviewer experimental conditions. As mentioned above, the accumulated results with the MBE experiment demonstrated a highly consistent bias effect, but this is not automatically self-understood: Viewers are exposed (for $83 \mathrm{~s}$ in seven interactional sequences) to a foreign, unknown interviewer who speaks an incomprehensible language, and he interviews an unknown candidate in a vague election campaign. Why would the viewers be at all susceptible to this interviewer's hidden persuasion?

In successful persuasion, the experimental manipulation (of which the viewers are, of course, not aware because they are exposed to only one emotional mode of the interviewer) would cause the viewers to adopt the interviewer's emotional mode to which they had been exposed. That would evolve out of their total experience of the interviewer. We can presume that such a process would occur among some of the viewers, but not others, and the goal of the present investigation was to examine the process where viewers' impressions of the interviewer would moderate and cause-or not cause-a media bias effect. We thought that the relevant literature to analyze this process is the source credibility literature.

Because source credibility is an important component in persuasion, it is also relevant to bias phenomena. Research and publications on this topic span more than six decades, from French and Raven's exposition (1959) of the sources of social power until today. In the 1960s, Markham (1965) wrote on the dimensions of source credibility of TV newscasters, and Griffin (1967) reviewed the contribution of source credibility studies to interpersonal trust in the communication process. McCrosky and Jenson's (1975) fundamental contribution defined the major dimensions of source credibility, and the two dual process theories of the 1980s (Chaiken et al., 1989; Petty \& Cacioppo, 1986) sealed the conceptualization of source credibility in persuasion. More recently, Pompitakpan (2004) wrote a critical review of five decades' evidence on source credibility, Kumkale et al. (2010) wrote about effects of source credibility in the presence or absence of prior attitudes, and Nadarevie et al. (2020) investigated various methodological designs and presentation formats.

Actually, research and theorizing about source credibility, persuasion, and attitude change were investigated in the verbal, cognitive domain. But researchers were largely 
aware that the traits and characteristics contributing to source credibility effects include powerful nonverbal aspects. Two important publications focused on nonverbal behavior in persuasion and credibility — one by Burgoon et al. (1990) and a recent review by Guyer et al. (2019) in this journal.

After much consideration and contemplation, we decided that the source credibility approach is less directly relevant to the present investigation. Instead, we decided to focus on the alternative conception of Epistemic Authority (Kruglanski et al., 2005), which seems more appropriate to the structure and design of the present study. We concentrate on investigating nonverbal media bias and seek to uncover the link with communicator's authority, but the methodological path of our research is directly the opposite of the conventional design of source credibility research. In typical source credibility studies, investigators initially construct the dimensions and attributes of the source's credibility, employ them as independent variables in experimental designs, and subsequently measure their influence on receivers' attitude change. In our research, the independent variables are interviewer's nonverbal friendliness or hostility - and these emotional modes are not parts of source credibility. The aspects and effects of source credibility must be derived from the viewers' perceptions of the overall style of the interviewer, irrespective of the friendly or hostile experimental conditions. This fits Kruglanski's (1989) theorizing in his theory of lay epistemology, and particularly his conceptualization of how people subjectively select their (credible) epistemic authorities.

Kruglanski's lay epistemic theory (Kruglanski, 1989; Kruglanski et al., 2005) presented a "unimodel of persuasion" (Kruglanski, 2004), where the central concept for dealing with source credibility was "epistemic authority". Like other conceptions of source credibility, it is assumed that people tend to rely on authority figures in their attempts to acquire knowledge on various topics. But, unlike the search for generalized, "objective" de-facto characteristics of authority in source credibility research, Kruglanski emphasized the subjective self-involvement of the person in assigning epistemic authority to particular figures (see also Zagzebski, 2012, in a philosophical perspective).

The empirical research on epistemic authority (Kruglanski, 1989; Kruglanski, et al., 2005) focused mainly on the selection processes in which individuals choose model figures to serve as epistemic authorities for them, but did not examine the actual social behavior of these authority figures. The epistemic authority is a hypothetical figure, a symbolic relevant role holder. In real life settings, people continuously observe their chosen epistemic authorities and interact with them. Therefore, some selected figures might have higher chances of attaining stability in their status, whereas others might lose their privileged status in the eyes of their followers. The well-known term "clay feet" reflects disappointment with selected idols following the accumulation of social information.

In the context of TV broadcasting, a media personality may well be chosen by viewers as an epistemic authority, and hence would readily be assigned with source credibility. And if the interviewer is inherently accepted as possessing epistemic authority, viewers could rely on his emotional tone in forming their impressions of the interviewee. Viewers would then follow the interviewer's lead, assuming that the interviewee is to be regarded positively (in the friendly interviewer condition) or negatively (in the hostile interviewer condition). 


\section{The Present Study}

The objectives of the present study were as follows:

1. To conduct yet another replication of the MBE experiment in the 2020s, following turbulent years in the conduct and norms of the public media.

2. To measure viewers' perceptions and attributions of the interviewer (in addition to the standard measurement of their perceptions of the interviewee) to enable an examination of the interviewer's epistemic authority (and/or source credibility). Toward this goal, viewers in the present study filled out the same attributes and characteristics questionnaire for the interviewee and for the interviewer.

\section{Method}

\section{Participants}

The participants were 105 students: 54 males (51\%) and 51 females (49\%) from the Hebrew University of Jerusalem and from the Axioma College-Preparatory School in Israel. Their ages ranged from 18 to 60 years $(M=21.35)$.

\section{Materials}

\section{Stimuli}

Two parallel videos of a made-up political interview (4 min. $3 \mathrm{~s}$. long) showed the same interviewer behaving in a friendly (in one version) or a hostile manner (in the other) toward the same interviewee. The videos were created and used by Babad (2005), ${ }^{1}$ and were picked from the original friendly or hostile clips of an interviewer from Babad's (1999) study, together with clips of a 'fake' interviewee (the "politician"). The confederate posing as the interviewee was a geology professor in his sixties who was interviewed about nonpolitical matters in the same studio setting as the originally broadcasted interviews. He was aware of the intended purpose of the clips that would be taken from his interview. The clips of the interviewee were identical in both versions (friendly and hostile) of the experimental interview, and summed up to $147 \mathrm{~s}$. (60.5\% of the total time). The two versions of the film differed only in the clips of the interviewer-friendly or hostile. The clips of the interviewer in both versions summed up to $83 \mathrm{~s}$. ( $34 \%$ of the total time). Due to the fact that all of the participants in the present study were Hebrew-speakers, the audio track was turned off, and the participants viewed only the visual/video channel (as was done in previous administrations of the MBE experiment in Israel).

\section{Questionnaires}

Two versions of the same questionnaire - differing in minor details-were used for viewers' ratings of the interviewer and the politician. Participants rated 20 personally and social attributes of the interviewer/politician: 12 personality/social attributes (convincing;

\footnotetext{
${ }^{1}$ All videos are accessible at http://www.youtube.com/user/NvStudy.
} 
intelligent; relaxed; trustworthy; competent; confident; genuine; enthusiastic; emotional; humorous; flexible; and optimistic); six "communication skills" (ability to express himself clearly; to cope with stress; to convince others; to inspire confidence; leadership ability; and forcefulness); and two ratings of personal appearance (handsome and healthy). The politician's questionnaire included three additional questions: "What are the politician's chances of being elected?"; "Would you personally (hypothetically speaking) vote for him?"; "How much did you, personally, like the politician?" The interviewer's questionnaire included one additional question for manipulation-check: "To what extent was the interviewer friendly toward the politician?" All ratings were made on 7-point scales, ranging from 1 (low) to 7 (high).

The introduction to the questionnaires read as follows: "Research has shown that people can form relatively accurate impressions after a brief exposure to the nonverbal behavior of another person. In this research, we ask for your impressions of a politician who was interviewed in an election campaign, and your impressions of the interviewer as well. You will view the interview with no sound (no audio), and therefore your impressions will be based on nonverbal (visual, or video) aspects only, such as facial expressions and body language." Participants were requested to fill-out all the ratings, and to make guesses when they were not sure, because-it was explained-"we are interested in first impressions, even if they are only half-formed".

\section{Procedure}

The participants were randomly assigned to one of two conditions: Friendly video $(n=42)$ or hostile video $(n=63)$. Participants from each condition watched one version of the video in small groups and were then asked to fill out the two questionnaires. They were not aware at all of the existence of a parallel movie. Respondents could not see each other's ratings and were not allowed to discuss any aspect with each other until they completed filling out all ratings. A full debriefing of the study and its objectives was given at the end of the session.

\section{Results}

\section{Media Bias Effect: Influence of Interviewer's Nonverbal Behavior on Viewers' Ratings of the Politician}

\section{Manipulation Check}

The manipulation check of the interviewer condition employed the last item in the interviewer questionnaire, which asked respondents to what extent the interviewer was friendly toward the politician. And indeed, the viewers in the friendly condition perceived the interviewer as more friendly than the viewers in the hostile condition $(M=4.68, S D=1.63$ for the friendly condition, and $M=3.51, S D=2.09$ for the hostile condition; $t\left[94^{2}\right]=2.979$, $p<0.01, d=0.60)$.

\footnotetext{
${ }^{2}$ Note that 9 responders did not answer to the manipulation-check question and hence excluded from this analysis.
} 
Table 1 Effects of Interviewer's Differential Behavior on Viewers' Ratings of the Interviewed Politician

\begin{tabular}{|c|c|c|c|c|c|c|}
\hline \multirow[b]{3}{*}{ Dependent variable } & \multicolumn{4}{|c|}{ Interviewer condition } & \multirow{3}{*}{$\begin{array}{l}\text { t test } \\
t(102)\end{array}$} & \multirow{3}{*}{$\begin{array}{l}\text { Effect size } \\
\text { Cohen's d }\end{array}$} \\
\hline & \multicolumn{2}{|c|}{ Friendly } & \multicolumn{2}{|c|}{ Hostile } & & \\
\hline & $M$ & $S D$ & $M$ & $S D$ & & \\
\hline $\begin{array}{l}\text { Overall composite of personality and } \\
\text { social attributes }\end{array}$ & 3.91 & 0.78 & 3.55 & 0.94 & $2.039 *$ & 0.407 \\
\hline Chances of being elected & 3.51 & 1.43 & 3.13 & 1.56 & 1.258 & 0.253 \\
\hline Personally vote for the politician & 3.10 & 1.79 & 2.44 & 1.70 & $1.870 *$ & 0.377 \\
\hline Personally like the politician & 3.50 & 1.70 & 2.76 & 1.64 & $2.233 *$ & 0.446 \\
\hline
\end{tabular}

$* p<.05$ (one-tailed)

Fig. 1 Effects of interviewer's differential behavior on viewers' ratings of the interviewed politician

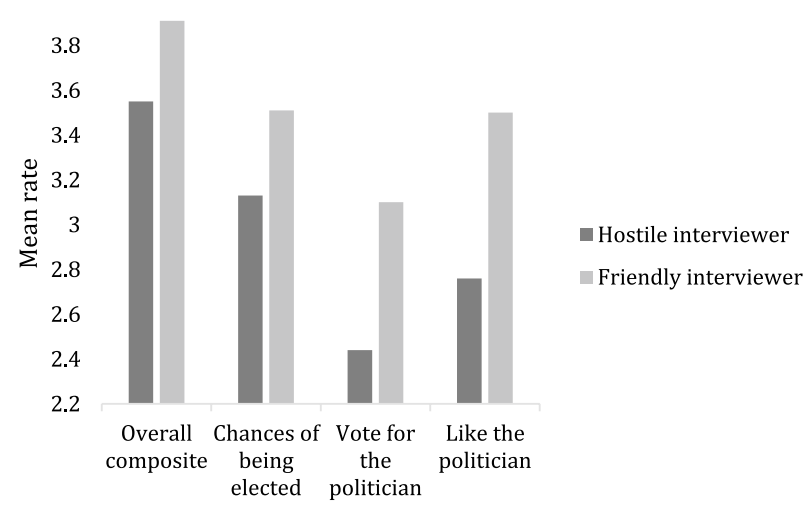

\section{Internal Consistency Reliability}

The internal consistency of the two questionnaires was computed via Cronbach's alpha coefficients. The reliability values were very high for both the interviewer's questionnaire ( $\alpha=0.888)$ and the politician's questionnaire $(\alpha=0.894)$.

\section{Dependent Variables}

The main dependent variable was the mean of all items in the politician's questionnaire (except for the last three items that differed from the rest of the questionnaire). This composite score represented viewers' overall impression across multiple social and personality attributes. The last three items were treated as separate dependent variables: chances of being elected; would personally vote for the politician; and personally liked the politician.

\section{Effect of Differential Interviewer's Behavior on Viewers' Ratings of the Politician: The MBE}

Table 1 presents the means, $S D s$, and $t$-test differences between the two interviewer conditions (friendly vs. hostile) for the four dependent variables, and Fig. 1 shows the patterns of 
Table 2 Principal Components Analysis of interviewer's attributes, with factor loadings for each variable

\begin{tabular}{lll}
\hline Items & \multicolumn{2}{l}{ Principal components } \\
\cline { 2 - 3 } & Authority & Expressivity \\
\hline Forcefulness & 0.719 & \\
Inspires Confidence & 0.710 & \\
Convincing & 0.703 & \\
Expresses himself clearly & 0.674 & \\
Intelligent & 0.658 & \\
Handsome & 0.639 & \\
Healthy & 0.621 & \\
Relaxed & 0.597 & \\
Trustworthy & 0.594 & \\
Copes with stress & 0.565 & \\
Competent & 0.565 & \\
Confident & 0.560 & \\
Leadership ability & 0.517 & 0.861 \\
Genuine & 0.438 & 0.757 \\
Enthusiastic & & 0.567 \\
Emotional & & 0.496 \\
Humorous & & 0.493 \\
Flexible & & \\
Optimistic & & \\
\hline
\end{tabular}

these results. The results were very consistent, and the politician received in all comparisons more positive ratings in the friendly, compared to the hostile interviewer condition. Thus, the MBE was clearly replicated in this sample. The difference between the experimental groups did not reach statistical significance for one dependent variable-chances of being elected. This is not surprising given that nothing at all was known to the judges about the candidate or what the election supposedly involved. The other three dependent variables constituted personal evaluations of the politician, and these were indeed significantly influenced by the interviewer's nonverbal behavior.

\section{Investigation of the Interviewer's Behavior}

Principal Components Analysis of the Interviewer's Behavior The questionnaire included 20 personality and social attributes. To reduce complexity and understand the internal structure of viewers' impressions of the interviewer, we conducted a series of exploratory analyses. The resultant central analysis was a Principal Components Analysis (PCA) that yielded two main factors (Eigen-Values 6.88 and 2.82) which included, after Varimax rotation, 19 of the 20 items in the questionnaire with factor loadings $>0.40$. [Six of seven items included in small factors in the exploratory analyses were now part of the two main factors with appropriately high loadings, and one item ("the ability to convince others") was excluded from the analysis].

The first factor (see Table 2) explained $26 \%$ of the variance (Eigen-value=6.876). The 14 items included in that factor described aspects of leadership, instrumentality and authority. We labeled this factor "Authority." The five items in the second factor 
Fig. 2 Means of the overall ratings of the interviewed politician as a function of the interviewer's preferential behavior (friendly vs. hostile) and perceived authority (high vs. low). Note. Error-bars represent $95 \%$ ConfidenceInterval

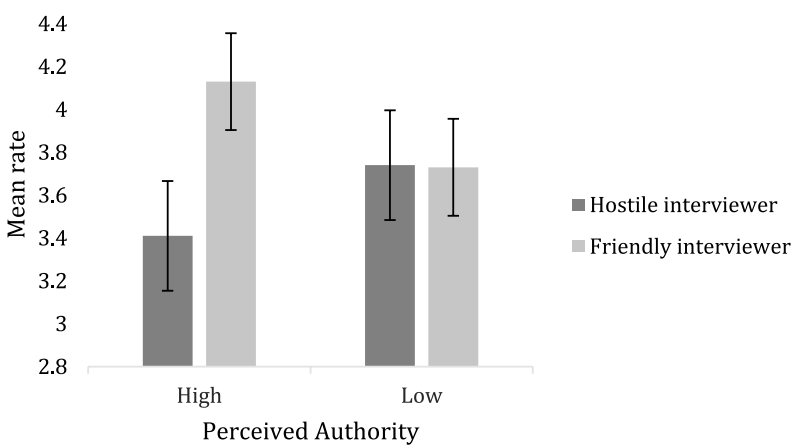

(Eigen-value $=2.815,15 \%$ explained variance) described warm affect and expressivity, and we labeled it "Expressivity." Subsequently, two composite scores-authority and expressivity — were computed, averaging viewers' ratings of the relevant items for each factor.

To determine whether these composite scores could be used as independent variables in the study design, the differences between the means of the two experimental groups (friendly versus hostile interviewer) were tested for the two composite scores. For the Authority composite, no difference was found between the experimental groups, $t(103)=0.476, p=0.634$. Therefore, we decided to use that composite as a new independent variable in our analysis. In contrast, a substantial difference was found for the Expressivity composite, and the interviewer was rated as significantly more expressive in the friendly, compared to the hostile condition, $M=4.20, S D=1.31$, and $M=3.51, S D=1.24$ respectively; $t(103)=2.731, p<0.01, d=0.54$. Thus, the experimental manipulation (friendly vs. hostile interviewer) and the expressivity composite were confounded and not sufficiently distinct from each other. Therefore, we decided to exclude the Expressivity composite from subsequent analysis.

Perceived Authority of the Interviewer as a Moderator of the Media Bias Effect To test whether the perceived authority of the interviewer would moderate the media bias effect, we computed a median-split on viewers' Authority ratings, dividing the respondents into new "high perceived authority" and "low perceived authority" groups. A subsequent 2X2 ANOVA examined the effects of perceived interviewer's authority (high versus low authority) and the interviewer's differential nonverbal behavior (friendly versus hostile interviewer condition) on respondents' overall ratings of the politician as the dependent variable.

The 2X2 ANOVA yielded a significant main effect for the experimental condition, $F(1$, $100)=4.253, p<0.05, \eta^{2}=0.039$; no main-effect for perceived authority, $F(1,100)=0.048$, $p=0.825$; and a significant interaction between the experimental condition and perceived authority, $F(1,100)=4.275, p<0.05, \eta^{2}=0.039$. The pattern of the results can be seen in Fig. 2. Among the respondents who perceived the interviewer as a high authority, those in the friendly interviewer condition rated the politician more positively than those in the hostile condition, $M=4.13, S D=0.82$ and $M=3.41, S D=0.93$ respectively; $t(52)=2.835$, $p<0.01, d=0.77$. On the other hand, no difference at all was found between the friendly and hostile interviewer conditions among respondents who perceived the interviewer as a low authority: for the friendly condition, $M=3.73, S D=0.72$; for the hostile condition, $M=3.74, S D=0.95 ; t(52)=0.024, p=0.98$. Our clear conclusion was that perceptions of the interviewer's authority moderated the viewers' ratings of the politician, and a media 
bias effect was found only for those who perceived the interviewer as a high authority. In other words, for the interviewer's (friendly versus hostile) nonverbal behavior to influence viewers' ratings of the interviewed politician, they must have perceived the interviewer as an (epistemic) authority figure.

\section{Discussion}

This research yielded two main results:

(1) The Media Bias Effect as administered and measured in the MBE experiment was replicated again in the 2020 s with no reduction in its intensity. The fact that the friendly versus hostile nonverbal behavior of an interviewer can cause a bias effect today as it did some years ago is significant. It means that the salient cultural changes in media conduct in recent years and the consequent decrease in public trust in media fairness and equity did not affect nor reduce the intensity of source credibility in TV persuasion. This is not selfunderstood, and old habits are probably hard to die. People seek to rely on credible sources for "knowing" how to process social information.

Political persuasion is usually considered more frequently in the verbal domain (effects of statements and content-centered arguments on attitude change). But the series of studies on the MBE experiment has recorded substantial effects caused by nonverbal behavior alone without any verbal content. Clear causal findings of this type do exist, but they are quite rare.

(2) Two distinct components emerged in the examination of the viewers' perceptions of the interviewer based on his overall nonverbal conduct—"authority" and "expressivity." The authority component was similar to the known conceptualizations of source credibility and epistemic authority, and it was independent of the experimental effect of friendly versus hostile interviewer's conditions. We computed a new composite score for "interviewer's authority" via a median split of the viewers' ratings for this component. Next, we conducted a 2X2 ANOVA of viewers' ratings of the interviewee, with interviewer's perceived authority (high vs. low) and interviewer's friendliness (friendly vs. hostile) as the independent variables. The results demonstrated that the interviewer's nonverbal behavior caused an MBE only for the group of viewers who perceived the interviewer as a high authority figure, and no bias effect for the group who perceived the interviewer as possessing low authority.

Thus, we found that source credibility (or more exactly epistemic authority, in our opinion) moderated the MBE caused by the interviewer's nonverbal behavior, so that the interviewer could influence (and bias) the viewers only if they perceived him as an authority figure. As mentioned above, these results are in line with the source credibility literature and support its general notion, but the contribution of the present study stems from its exclusively nonverbal emphasis and from its unique methodology. Ever since "central and peripheral routes to attitude change" (Petty \& Cacioppo, 1986) source credibility was a cognitive construct based on verbal thoughts and arguments of figures possessing particular measurable traits. But a recent review (Guyer et al., 2019, with Petty himself as a coauthor) provided a multiple-process analysis of nonverbal behavior of persuasive sources.

In designing this study, we chose to abandon the conventional source credibility methodology of pre-determining attributes of credibility and assigning them as fixed independent variables. Instead, we followed the epistemic authority thinking and focused the investigation on viewers' subjective perceptions of the interviewer, thereby allowing the emergence of a new source of variance about the source's authority. In this approach, the 
fixed (presumably "true") characteristics of the interviewer have no causal power in themselves, and credibility is derived from receivers' subjective perceptions, so that the very same stimulus materials (i.e., the interviewer's overall nonverbal conduct) can evoke a whole range of attributions among different viewers.

Having established this new, conceptually-based source of variance, we proceeded to examine whether subjective perceptions of epistemic authority would moderate the MBE. The results of this new method of analysis indeed confirmed the basic ideas and predictions of the source credibility conception, without the assignment of pre-determined attributes of authority.

The contribution of this research to the Epistemic Authority literature is in the affirmation of both Kruglanski's and Zagbeski's conceptual emphasis of the subjective nature of the epistemic authority phenomenon and the self-involvement of the person in assigning epistemic authority to a potential source. Both Krugkanski and Zagbeski have made this argument, but it has not been empirically examined before.

Our concluding comment concerns a somewhat ironic twist about the dissonance between the intuitive "end states" of source credibility research on the one hand and media bias research on the other hand. In folk culture, every psychological construct would have a desirable end state, a globalized goal, or wish in people's eyes. In bias research, that goal would be to increase people's independent thinking and objective information processing and to reduce bias. Therefore, it would be nice if TV viewers would not be influenced by the interviewer's friendly or hostile nonverbal behavior. In source credibility research, we would probably wish to see a smooth and harmonious process of leadership influence, so that the figures to whom we assign epistemic authority would indeed prove to be effective leaders.

In the social situation of the present research, the attainment of one folk goal comes at the expense of the other. If viewers accept the epistemic authority of the interviewer, they would more likely become influenced and biased by the interviewer's conduct. To prevent bias, the assignment of epistemic authority to the interviewer must be disappointed, and he should be perceived as a non-effective leader!

Acknowledgements We would like to thank Lital Atar-Zeitsl and David Kenigsberg for their assistance with this work, Dinah Avni-Babad for her advice, and Eyal Peer for his continued participation over the years. The meaningful contribution of the late John Darley of Princeton University in the initial thinking about the MBE studies is appreciated and very fondly remembered.

\section{References}

Babad, E. (1999). Preferential treatment in television interviewing: Evidence from nonverbal behavior. Political Communication, 16(3), 337-358. https://doi.org/10.1080/105846099198668

Babad, E. (2005). The psychological price of media bias. Journal of Experimental Psychology: Applied, 11(4), 245-255. https://doi.org/10.1037/1076-898X.11.4.245

Babad, E., \& Peer, E. (2010). Media bias in interviewers' nonverbal behavior: Potential remedies, attitude similarity and meta-analysis. Journal of Nonverbal Behavior, 34(1), 57-78. https://doi.org/10.1007/ s10919-009-0078-X

Babad, E., Peer, E., \& Benayoun, Y. (2012a). Can multiple biases occur in a single situation? Evidence from media bias research. Journal of Applied Social Psychology, 42(6), 1486-1504. https://doi.org/10. 1111/j.1559-1816.2012.00909.x

Babad, E., Peer, E., \& Hobbs, R. (2012b). Media literacy and media bias: Are media literacy students less susceptible to nonverbal judgment biases? Psychology of Popular Media Culture, 1(2), 97-107. https:// doi.org/10.1037/a0028181 
Banning, S., \& Coleman, R. (2009). Louder than words: A content analysis of presidential candidates' televised nonverbal communication. Visual Communication Quarterly, 16, 4-17.

Boxwell, L. (2018). Slanted images: Measuring nonverbal media bias. MPRA: Munich Personal RePEc Archive_paper_89047.pdf

Burgoon, J., Birk, T., \& Pfan, M. (1990). Nonverbal behavior, persuasion, and credibility. Human Communication Research, 17, 140-169.

Chaiken, S., Lieberman, A., \& Eagly, A. (1989). Heuristic and systematic information processing within and beyond the persuasion context. In J. Uleman \& J. Bargh (Eds.), Unintended thought (pp. 212-252). Guilford Press.

Cohn, N. (2020, November 10). What went wrong with polling? Some early theories. The New York Times. Retrieved May 10, 2020 from https:/www.nytimes.com/2020/11/10/upshot/polls-what-went-wrong. html

Dumitrescu, D. (2016). Nonverbal communication in politics: A review of research developments. American Behavioral Scientist, 60, 1656-1675.

Elliott, D. (1986). Responsible journalism. Sage.

French, J., \& Raven, B. (1959). The bases of social power. In D. Cartwright (Ed.), Studies in social power (pp. 150-167). University of Michigan.

Friedman, H. S., DiMatteo, M. R., \& Mertz, T. I. (1980a). Nonverbal communication on television news: The facial expressions of broadcasters during coverage of a presidential election campaign. Personality and Social Psychology Bulletin, 6(3), 427-435. https://doi.org/10.1177/014616728063016

Friedman, H., Mertz, T., \& DiMatteo, R. (1980b). Perceived bias in the facial impressions of television news broadcasters. Journal of Communication, 30, 103-111.

Grebelsky-Lichtman, T. (2010). The relationship of verbal and nonverbal behavior to political stature: The political interviews of Israel's prime minister Ariel Sharon. Journal of Political Marketing, 9, 229-253.

Grebelsky-Lichtman, T. (2016). The role of verbal and nonverbal behavior in televised political debates. Journal of Political Marketing, 15, 362-387.

Grebelsky-Lichtman, T., \& Katz, R. (2020). Gender effect on political leaders' Nonverbal communicative structure during the COVID-19 crisis. International Journal of Environmental Research and Public Health, 17(21), 789. https://doi.org/10.3390/ijerph17217789

Griffin, K. (1967). The contribution of studies on source credibility to a theory of interpersonal trust in the communication process. Psychological Bulletin, 68, 104-120.

Guyer, J., Brinol, P., Petty, R., \& Horcajo, J. (2019). Nonverbal behavior of persuasive sources: A multiple Process Analysis. Journal of Nonverbal Behavior, 43, 203-231.

Haumer, F., \& Donsbach, W. (2009). The rivalry of nonverbal cues on the perception of politicians by television viewers. Journal of Broadcasting and Electronic Media, 53, 262-279.

Kilgo, D., Boulter, T., \& Coleman, R. (2018). Face value: Linking nonverbal cues to character traits in impressions formation of politicians. International Journal of Communication, 12, 4205-4228.

Kinoshita, K. (2020). Japanese political interviews: The integration of conversation analysis and facial expression analysis. Asian Journal of Public Opinion Research, 8, 180-196.

Kruglanski, A. (1989). Lay epistemics and human knowledge: Cognitive and motivational bases. Plenum Press.

Kruglanski, A. (2004). The quest for the gist: On challenges of going abstract in social and personality psychology. Personality and Social Psychology Review, 8, 156-163.

Kruglanski, A. W., Raviv, A., Bar-Tal, D., Raviv, A., Sharvit, K., Ellis, S., \& Mannetti, L. (2005). Says who? Epistemic authority effects in social judgment. Advances in Experimental Social Psychology, 37, 345-392.

Kumkale, G., Albarracin, D., \& Seignourel, P. (2010). The effects of source credibility in the presence or absence of prior attitudes: Implications for the design of persuasive communication campaigns. Journal of Applied Social Psychology, 40, 1325-1356.

Markham, D. (1965). The dimensions of source credibility of television. University of Oklahoma.

McCrosky, J., \& Jenson, T. (1975). Image of mass media news sources. Journal of Broadcasting, 19, $169-180$.

Mullen, B., Futrell, D., Stairs, D., Tice, D. M., Baumeister, R. F., Dawson, K. E., Riordan, C. A., Radloff, C. E., Goethals, G. R., Kennedy, J. G., \& Rosenfeld, P. (1986). Newcasters' facial expressions and voting behavior of viewers: Can a smile elect a president? Journal of Personality and Social Psychology, 51(2), 291-295. https://doi.org/10.1037/0022-3514.51.2.291

Nadarevie, L., Reber, R., Helmeeke, A., \& Kose, D. (2020). Perceived truth of statements and simulated social media postings: An experimental investigation of source credibility, repeated exposure, and 
presentation format. Cognitive Research: Principles and Implications, 5, 50. https://doi.org/10.1186/ s41235-020-00251-4

Olivola, C., \& Todorov, A. (2010). Elected in 100 milliseconds: Appearance-based trait inferences and voting. Journal of Nonverbal Behavior, 34, 83-110. https://doi.org/10.1007/s10919-009-0082-1

Peng, Y. (2018). Same candidates, different faces: Uncovering media bias in visual portrayals of presidential candidates with computer vision. Journal of Communication, 68, 920-941.

Petty, R., \& Cacioppo, J. (1986). Communication and persuasion: Central and peripheral routes to attitude change. Springer.

Pompitakpan, C. (2004). The persuasiveness of source credibility: A critical review of five decades' evidence. Journal of Applied Social Psychology, 34, 243-281.

Price, V., \& Stroud, N. (2005). Public attitudes toward polls: Evidence from the 2000 U.S. presidential election. International Journal of Public Opinion Research, 18, 393-421.

Rogel, N., \& Shejter, A. (1995). The Nakdi document: Guidelines for broadcasting news and current affairs. Israel Broadcasting Authority.

Schroder, A. (2016). Presidential debates: Risky business on the campaign trail. Columbia University Press.

Sheffield, M. (2018, December 27). Survey: A majority of American don't believe polls are accurate. The Hill. Retrieved April 15, 2020 from https://thehill.com/hilltv/what-america-thinking/423023-a-major ity-of-americans-are-skeptical-that-public-opinion-polls

Trotta, D., \& Tonelli, S. (2021). Are gestures worth a thousand words? An analysis of interviews in the political domain. In Proceedings of the 1st workshop on multimodal semantic representations (MMSR) (pp. 11-20).

Zagzebski, L. T. (2012). The moral authority of exemplars. In J. A. Van Slyke, G. Peterson, W. S. Brown, K. S. Reimer, \& M. Spezio (Eds.), Theology and the science of moral action (pp. 129-141). Routledge.

Publisher's Note Springer Nature remains neutral with regard to jurisdictional claims in published maps and institutional affiliations. 